\title{
Seasonal variations in active microwave signatures of sea ice in the Greenland Sea during 1992 and 1993
}

Thomsen, Bjørn Bavnehøj; Skriver, Henning; Pedersen, Leif Toudal

Published in:

Proceedings of the International Geoscience and Remote Sensing Symposium

Link to article, DOI:

10.1109/IGARSS.1995.520481

Publication date:

1995

Document Version

Publisher's PDF, also known as Version of record

Link back to DTU Orbit

Citation (APA):

Thomsen, B. B., Skriver, H., \& Pedersen, L. T. (1995). Seasonal variations in active microwave signatures of sea ice in the Greenland Sea during 1992 and 1993. In Proceedings of the International Geoscience and Remote Sensing Symposium: Quantitative Remote Sensing for Science and Applications (Vol. 1, pp. 644-646). IEEE. https://doi.org/10.1109/IGARSS.1995.520481

\section{General rights}

Copyright and moral rights for the publications made accessible in the public portal are retained by the authors and/or other copyright owners and it is a condition of accessing publications that users recognise and abide by the legal requirements associated with these rights.

- Users may download and print one copy of any publication from the public portal for the purpose of private study or research.

- You may not further distribute the material or use it for any profit-making activity or commercial gain

- You may freely distribute the URL identifying the publication in the public portal 


\title{
Seasonal Variations in Active Microwave Signatures of Sea Ice in the Greenland Sea during 1992 and 1993
}

\author{
Bjørn Bavnehøj Thomsen, Henning Skriver and Leif Toudal Pedersen \\ Danish Center for Remote Sensing, Electromagnetics Institute \\ Technical University of Denmark, Building 348, DK-2800 Lyngby, Denmark \\ Phone: +45 45881444 Fax: +45 45931634 E-mail: bbt@emi.dtu.dk
}

\begin{abstract}
Derivations of the microwave signatures of sea ice have often been focused on the backscatter coefficient $\sigma^{\circ}$. It is well known that $\sigma^{\circ}$ is rather stable during winter and varies a lot during summer due to the complex mechanisms related to melting. However, less work has been carried out into the research of other statistical features of the sea ice than the mean value and also their seasonal variations. This paper investigates the backscatter coefficient and texture of different sea ice types and water by using calibrated precision images (PRI) acquired by the Synthetic Aperture Radar (SAR) on board the ERS-1 satellite. Seasonal variations have been related to the meteorological conditions and the radar system parameters.
\end{abstract}

\section{INTRODUCTION}

This work has primarily been dealing with investigation of the backscatter coefficient and variation from areas containing either first-year ice, multiyear ice or water. The work has concentrated on the area of the North East Water Polynya (NEW Polynya) extended into the Greenland Sea.

The ice situation in the NEW Polynya is both during winter and summer affected by wind and ocean currents guided by bathymetry. Strong wind from North has been observed to extend the area of the polynya dramaticly, even during winter. The bathymetry causes an anticyclonic current going northward very close to the eastern coast of Greenland. This also seems to be an important factor in the movement of the ice.

During winter the sea ice is rather stable in terms of microwave backscattering. Depending on ice type, the measured backscatter values are affected by backscattering mechanisms at the surface or in the sea ice layer. A layer of dry snow on top of the ice, will react invisible to the microwaves.

The onset of melting affects the microwave signatures dramatically. Wetness of the snow layer causes a large attenuation. The penetration depth decreases and the microwave signatures are affected by scattering in the usually very smooth air-snow surface. Later cooling, drying and drainage of the ice floe can cause $\sigma^{\circ}$ to increase [1].

Studies in Antarctic areas have shown that layers in the ice can be affected by a melting-freezing process during a day-night cycle, causing the backscatter coefficient to be dependent on the acquisition time of the scene [2].

In [3] it was found that the power-to-mean-squared ratio (PMR) adds important information when "discriminating water from ice. The texture parameter variance-to-meansquared ratio (VMR) can be directly derived from PMR, since $\mathrm{VMR}=\mathrm{PMR}-1 . \mathrm{VMR}$ is defined as

$V M R\{X\}=V\{X\} / E\{X\}^{2}$

where $E\{X\}$ is the expected value and $V\{X\}$ is the variance.

During a classification process, large segments of water, multiyear ice and first-year ice were evaluated with respect to VMR. For water it was found to be $0.35-0.47$, for multiyear ice 0.57-0.77, and for first-year ice 0.34-0.88. The ranges are derived from [3] using the most extreme values of $\mu \pm \sigma$, where $\mu$ is the mean value of VMR and $\sigma$ is the standard deviation.

\section{DATA AND METHODS}

A total of 42 scenes from 15 different orbits have been received as precision products (ERS-1.SAR.PRI) from the ESA Processing and Archive Facilities in U.K. and Germany (UK-PAF and D-PAF). All images have been compensated for illuminated area following the algorithm in [4], and stored in an internal image format used at the Electromagnetics Institute. Images not compensated for range spreading loss or antenna pattern when received from D-PAF or UK-PAF, have been corrected when processing the scenes to the internal image format.

The scenes covered the period 28 May 1992 to 25 July 1993. Within the scenes different areas of first-year ice, multiyear ice and water were selected and the statistical properties were investigated. Beside the mean value, also VMR was used in the analysis.

To handle the large amount of data, all scenes have been reduced in size by a factor of 8 in both directions. The averaging process was performed as

$A=\sqrt{\sum I_{i j}}=\sqrt{\sum A_{i j}^{2}}$

where $i, j$ is the index of the pixel, $A$ is the amplitude of the received signal, and $I=A^{2}$ is the intensity. This process does not affect the measured mean value of $\sigma^{\circ}$, but texture parameters are indeed affected. Reduction of speckle in this way is denoted multilook by spatial diversity.

If an area is inhomogeneous, i.e. contains some kind of variation in the backscatter coefficient, the VMR will be higher than VMR for a homogeneous area. If the real backscatter coefficient of the area follows a Gaussian distribution, and the speckle effect from the radar system follows a gamma distribution, then the distribution of the measured intensity $I$ is given by

$I \in \Gamma(k, \lambda) N\left(\left\langle\sigma^{\circ}\right\rangle, \sigma_{\sigma^{\circ}}^{2}\right)$ 
where $k$ is the form parameter and $\lambda$ the scale parameter in the gamma distribution, and $\left\langle\sigma^{\circ}\right\rangle$ is the mean value and $\sigma_{\sigma^{\circ}}$ the standard deviation of the backscatter coefficient. Since the mean value of the intensity is equal to the mean value of the backscatter coefficient, the scale parameter is given by $\lambda=1 / k$.

If the two stochastic processes are independent, VMR can now, according to [6], be approximated by

$V M R\{I\}=1 / k+\left(\sigma_{\sigma^{\circ}} /<\sigma^{o}>\right)^{2}$.

Traditionally areas of water are considered as homogeneous in SAR images if the wind field is uniform. However according to the CMOD4 model [7] relating backscatter levels with wind speed and direction, the change in $\sigma^{0}$ can exceed $1 \mathrm{~dB}$ per degree change in incidence angle.

In a PRI image (orbit 291 frame 2439) located east of Sweden, a subset of 4096 lines (azimuth) and 512 samples (range) with center at $57.6993^{\circ} \mathrm{N}, 20.8562^{\circ} \mathrm{E}$ has been used to investigate the influence of the averaging process. The subset was found in a very homogeneous area. It is narrow in the range direction in order to reduce the variance of $\sigma^{o}$ related to different incidence angles.

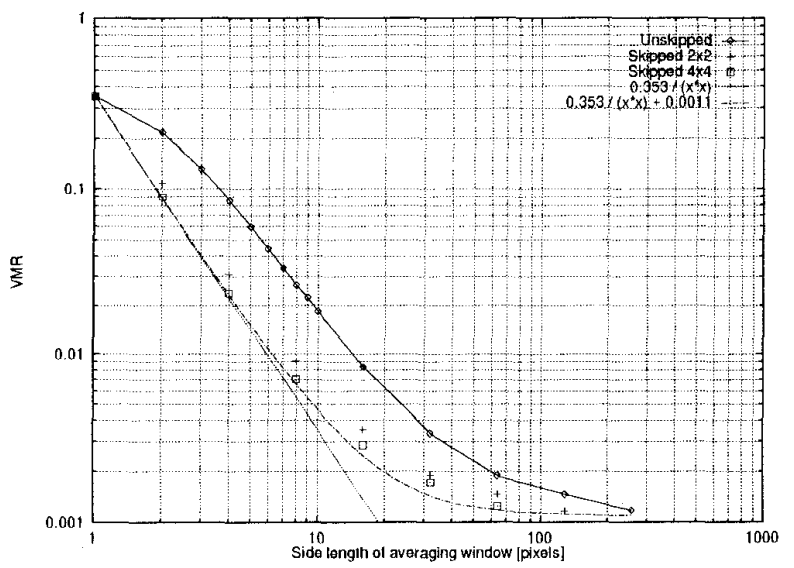

Figure 1: Variance-to-Mean-squared Ratio (VMR) of water area when using skip and average filter. A VMR level of 0.0011 corresponds to a relative standard deviation of $0.14 \mathrm{~dB}$. Equivalent number of looks (ENL) can be found as 1/VMR.

In Figure 1 it is shown how VMR decreases as the image values are speckle reduced by averaging. VMR is plotted against the side length of the averaging window. When a new subset is made by skipping pixels, the pixels are expected to be less correlated. Already by skipping every second row and column, the measured VMR is close to the VMR modelled by (4) where the VMR coming from the Gaussian distribution is estimated to 0.0011 .

From Figure 1 it is also concluded that the Equivalent Number of Looks (ENL) from an ERS-1 SAR PRI image averaged by $8 \times 8$ pixels is 39.2 looks. This should be compared to the ENL of 2.84 in case the image is not averaged.

\section{RESULTS}

Meteorological data from an automatic weather station at Kroyers Holme $\left(80.651^{\circ} \mathrm{N}, 13.722^{\circ} \mathrm{W}\right)$ run by the Danish Meteorological Institute, shows that the first day when two consecutive measurements of the temperature are above the freezing point, is located on 15th June ( \pm 1 day) for 1993 and 1994 . The last day is observed to be 2nd September ( \pm 3 days) during 3 years.

Figure 2 shows $\sigma^{\circ}$ from areas of multiyear ice, first-year ice and water. From Figure 2, that clearly shows the seasonal variation in the backscatter, a summer period is defined as from late May to start of September, and a winter period is defined as the remaining part of the year.

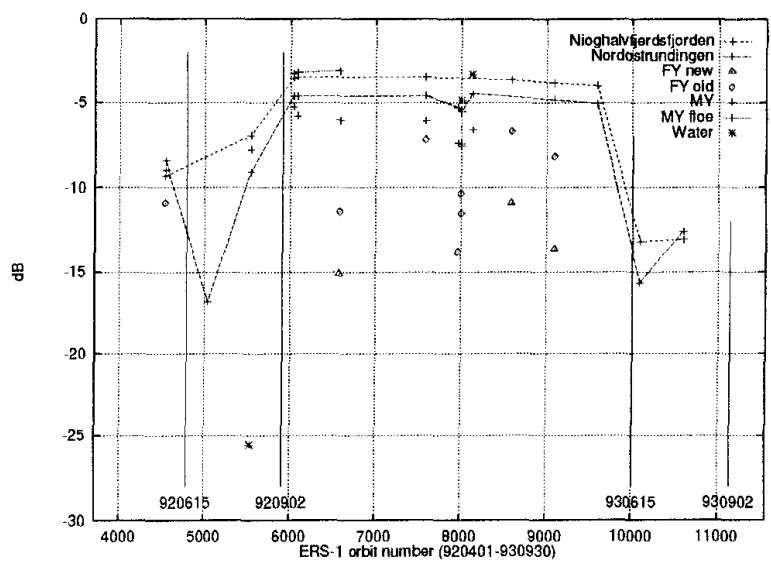

Figure 2: $\sigma^{\circ}$ of various areas with indications of first and last dates with positive temperatures.

During winter, $\sigma^{\circ}$ from multiyear ice is very stable. The maximum observed variation within the same floe is $1 \mathrm{~dB}$, and the total variation is $2.4 \mathrm{~dB}$ from -5.5 to $-3.1 \mathrm{~dB}$. The onset of melting is clearly observed in Figure 2, as $\sigma^{\circ}$ drops more than $8 \mathrm{~dB}$ when the surface becomes wet. During summer, $\sigma^{\circ}$ increases and reach a stable value at the latest by start of September. First-year ice could not be identified in the summer periods except for a single observation in the early summer 1992 . In the winter period large variations within the range -15.1 to $-6.7 \mathrm{~dB}$ occured. Water areas show large variations from -25.5 to $-3.4 \mathrm{~dB}$ due to different wind conditions.

Figure 3 shows VMR from the same areas as Figure 2. VMR also seems stable during the winter period for multiyear ice, but with a small trend of increasing values with time. Values was observed within 0.09 to 0.21 during winter and within 0.06 to 0.19 during summer. The minimum values in summer are observed after the minimum in the mean value of $\sigma^{\circ}$ occurs, and are explained by wet and smooth surfaces. The increasing trend in VMR implies an increased variance, since $\sigma^{\circ}$ was observed to be very stable for multiyear ice.

First-year ice areas have much higher variations in VMR than multiyear ice. The areas with low values of $\sigma^{\circ}$ clearly show high values of VMR in the range 0.40 to 1.80 . Areas with higher $\sigma^{\circ}$ have lower values of VMR. 
Water areas are observed to have very low VMR values (less than 0.06) as expected, since water is usually considered to be homogeneous.

Table A shows the range of $\sigma^{\circ}$, and the standard deviation of $\sigma^{\circ}$ estimated from VMR by (4) with $k=39.2$.

\begin{tabular}{|l|r|r|r|c|}
\hline Type & $\sigma_{\min }^{o}$ & $\sigma_{\max }^{o}$ & $\sigma_{\sigma^{\circ}, \min }$ & $\sigma_{\sigma^{\circ}, \max }$ \\
\hline \hline FY-1 & $-13.8 \mathrm{~dB}$ & $-6.7 \mathrm{~dB}$ & $\pm 0.4 \mathrm{~dB}$ & $\pm 1.7 \mathrm{~dB}$ \\
\hline FY-2 & $-15.1 \mathrm{~dB}$ & $-10.9 \mathrm{~dB}$ & $\pm 2.1 \mathrm{~dB}$ & $\pm 3.7 \mathrm{~dB}$ \\
\hline MY-W & $-5.5 \mathrm{~dB}$ & $-3.1 \mathrm{~dB}$ & $\pm 1.0 \mathrm{~dB}$ & $\pm 1.6 \mathrm{~dB}$ \\
\hline MY-S & $-16.8 \mathrm{~dB}$ & $-6.9 \mathrm{~dB}$ & $\pm 0.7 \mathrm{~dB}$ & $\pm 1.5 \mathrm{~dB}$ \\
\hline WATER & $-25.5 \mathrm{~dB}$ & $-3.4 \mathrm{~dB}$ & $\pm 0.3 \mathrm{~dB}$ & $\pm 0.7 \mathrm{~dB}$ \\
\hline
\end{tabular}

Table A: Minimum and maximum mean value of $\sigma^{\circ}$ and estimated minimum and maximum standard deviation of $\sigma^{\circ}$.

The conclusion is that multiyear ice is very stable from September to May in terms of microwave backscatter, but from May to September melting mechanisms affects both $\sigma^{\circ}$ and VMR, due to wet and smooth surfaces.

First-year ice is very difficult to identify in the summer period. During winter, large variations in both $\sigma^{\circ}$ and VMR have been observed. Visual studies of VMR show that areas of first-year ice are composed of areas with very low VMR and ridges with very high VMR. If the measured areas contains both smooth first-year ice and ridges, the resulting VMR will be higher for areas of first-year ice with lower backscatter, since VMR represents the ratio between variance and squared intensity.

Areas of frozen leads was observed to increase by $2 \mathrm{~dB}$ in only 3 days ${ }^{1}$. This observation follows other indications of young ice increasing in backscatter level with time. However, care should be taken, since convergence of the ice was observed, which might have caused rafted ice.

Other examples have been observed where multiyear ice probably have broken up followed by freezing of the leads. It leaves structures of various levels of lower backscatter, where brighter levels tend to be closer to the border between new and old ice, probably explained by several iterations of the break-up/refreeze process.

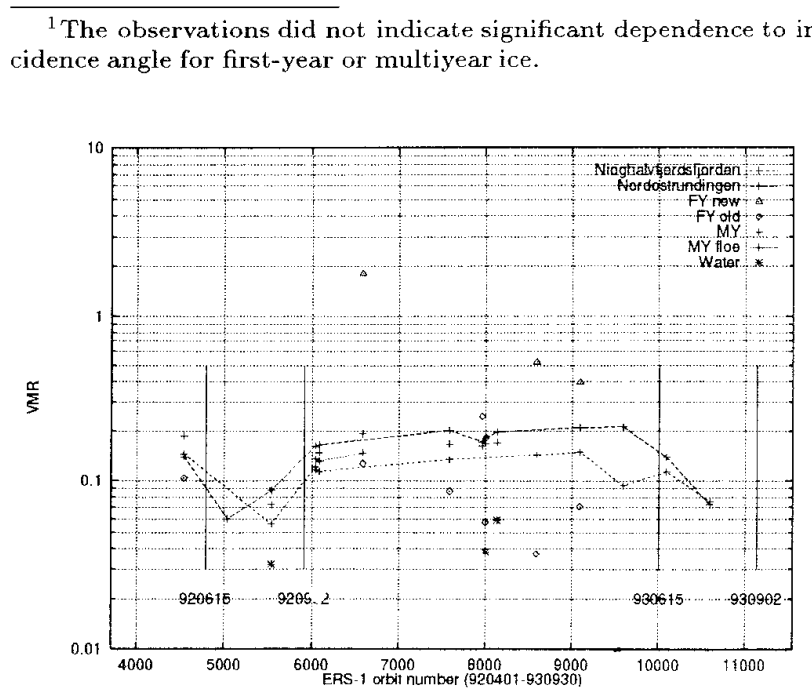

Figure 3: VMR of various areas with indications of first and last dates with positive temperatures.

\section{DISCUSSION}

The variation in the real backscatter coefficient was derived in PRI images averaged by $8 \times 8$ pixels. Variations were lower than else reported since the real $\sigma^{\circ}$ was also averaged by $8 \times 8$ pixels.

Multiyear ice showed to be very stable from September to May in terms of backscatter, but after onset of melting large drops in both $\sigma^{\circ}$ and VMR occured due to wet and smooth surfaces.

First-year ice showed large variations in both $\sigma^{\circ}$ and VMR. The variations in $\sigma^{\circ}$ were related to the age of the ice and caused by cooling and drying, and the variations in VMR was related to ridges.

Water showed large variations in $\sigma^{\circ}$ due to different wind conditions, but was very stable in terms of VMR.

\section{ACKNOWLEDGMENT}

The work has been carried out with financially support by the Danish Space Research Board. The Danish Meteorological Institute have provided meteorological data under the European Union MAST-II programme. Thanks are also extended to professor Preben Gudmandsen and staff at the Danish Center for Remote Sensing (DCRS) for valuable discussions. DCRS is sponsored by the Danish National Research Foundation.

\section{REFERENCES}

[1] Gogeneni, S. P. et al, "The Effects of Freeze-Up and Melt Processes on Microwave Signatures", Microwave Remote Sensing of Sea Ice, Geophysical Monograph 68, American Geophysical Union, 1992, pp. 329-340.

[2] Aldworth, E., "Snow and Ice Characteristics of the Bellinghausen Sea, during the Spring Melt", Deep-Sea Research II, in press.

[3] Skriver, H., "On the accuracy of estimation of ice type concentration from ERS-1 SAR images", Proceedings 14th EARSeL Symposium, Gothenborg 1994.

[4] Laur, H., "Derivation of Backscatter Coefficient $\sigma^{\circ}$ in ERS1.SAR.PRI Products", ESA, 1992.

[5] Madsen, S. N., "Speckle Theory, Modelling, Analysis and Applications Related to Synthetic Aperture Radar Data", Ph.D. Thesis, Electromagnetics Institute, LD 62, Technical University of Denmark, 1986.

[6] Conradsen, K., "En introduktion til statistik" (in Danish), The Institute of Mathematical Statistics and Operations Research, Technical University of Denmark, 1984.

[7] Lecomte, P., "CMOD4 Model Description", ESA, ER-TNESA-GP-1120, March 1993. 